\title{
Influence of Wet Annealing on the Performance of SiZnSnO Thin Film Transistors
}

\author{
Sangmin Han and Sang Yeol Lee ${ }^{\dagger}$ \\ Department of Semiconductor Engineering, Cheongju University, Cheongju 360-764, Korea
}

Received June 30, 2014; Revised July 25, 2014; Accepted January 20, 2015

\begin{abstract}
Amorphous SiZnSnO(SZTO) thin film transistors(TFTs) have been fabricated by RF magnetron sputtering process, and they were annealed in air and in wet ambient. The electrical performance and the structure were analyzed by $\mathrm{I}-\mathrm{V}$ measurement, XPS, AFM, and XRD. The results showed improvement in device performance by wet annealing process compared to air annealing treatment, because free electron was shown to be increased due to reaction of oxygen and hydrogen generating oxygen vacancy. This is understood by the generation of free electrons. We expect the wet annealing process to be a promising candidate to contributing to high electrical performance of oxide thin film transistors for backplane device applications.
\end{abstract}

Keywords: Wet annealing, SZTO TFT, XRD, AFM, XPS

\section{INTRODUCTION}

Amorphous oxide semiconductor (AOS) such as ZnO-based thin film transistors (TFTs) have attracted much attention for their application to integrated circuits used in backplane of active matrix displays. They have higher electrical and optical property than that of amorphous silicon thin film transistors (a-Si TFTs), and their production cost is low compared with the low-temperature polycrystalline silicon (LTPS). Recently, there have been many reports on different materials for active layer of AOS TFTs. Among them, the most extensively used material is amorphous indium-gallium-zinc-oxide (a-IGZO). The a-IGZO TFTs exhibit high field effect mobility $\left(>10 \mathrm{~cm}^{2} / \mathrm{V} \mathrm{s}\right)$ in the mobility enhancer like indium [1]. However, indium is an expensive and rare material. Therefore, indium-free materials like zinc tin oxide (ZTO), have been studied intensively in these days $[2,3]$. Most of AOS TFTs are annealed for the improvement of electrical performance and stability of device, after deposition at room temperature (RT). Therefore, it is very important to optimize the

${ }^{\dagger}$ Author to whom all correspondence should be addressed:

E-mail: sylee@cju.ac.kr

Copyright $(2015$ KIEEME. All rights reserved.

This is an open-access article distributed under the terms of the Creative Commons Attribution Non-Commercia
License (http://creativecommons.org/licenses/by-nc/3.0) which permits unrestricted noncommercial use, distribution, and reproduction in any medium, provided the original work is properly cited. annealing process [4,5].

Through our studies and reference of other groups, we expected that hydrogen is not only used for generation of free electrons but also for the passivation effect of oxygen vacancy. However, the role of hydrogen in the wet annealing treatment is not clear yet, so the study is still in progress.

In this paper, we have fabricated silicon zinc tin oxide (SZTO) TFTs without indium, and we have annealed and compared them in the air and in wet ambient. TFTs have been annealed followed by the completed fabrication of SZTO TFT, and the performance of TFT has been compared by the annealing conditions.

\section{EXPERIMENTS}

SZTO films were deposited by radio frequency (RF) magnetron sputtering on a $\mathrm{SiO}_{2}(200 \mathrm{~nm}) / \mathrm{p}$-type $\mathrm{Si}$ (heavily doped) substrate at room temperature with the bottom gate structure. Figure 1 shows the schematic diagram of SZTO TFT structure. The magnetron sputtering was conducted in a mixed atmosphere of $\mathrm{O}_{2}$ and $\mathrm{Ar}$ (flow rate ratio of 1:9), by supplying an RF power of $50 \mathrm{~W}$. The SZTO film thickness was about $40 \mathrm{~nm}$ and was patterned by using photolithography. The width and length of the channel are $250 \mu \mathrm{m}$ and $50 \mu \mathrm{m}$, respectively. After deposition of the SZTO films, source and drain electrodes (Ti/Au=10 nm/50 nm) 


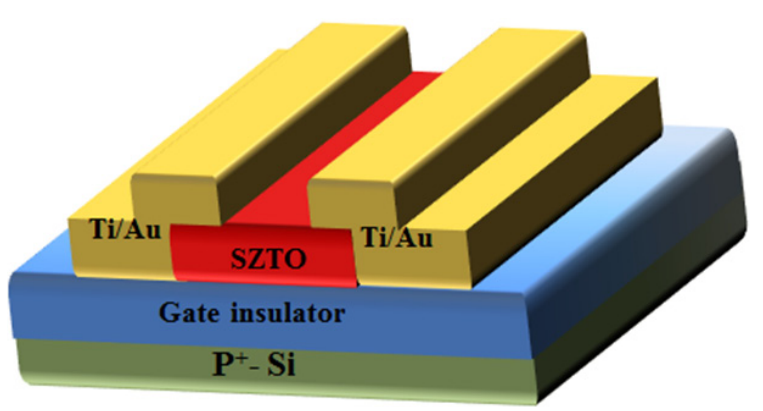

Fig. 1. Schematic diagram of SZTO TFTs structure.

were fabricated by e-beam evaporation and lift off process. Then, annealing process was performed in different annealing conditions, such as in air and in wet ambient.

The SZTO TFT was annealed at $500^{\circ} \mathrm{C}$ for $2 \mathrm{~h}$. Air annealing treatment was performed in atmospheric condition, while wet annealing was performed in the ambient of heated de-ionized (DI) water.

The amorphous structure of SZTO thin films was confirmed by X-ray diffraction (XRD). All electrical performances and stress characteristics were measured by using a semiconductor parameter analyzer (EL-423).

\section{RESULTS AND DISCUSSION}

Figure 2 shows XRD patterns of SZTO thin films on heavily doped p-type Si wafer. Most of the peaks are well-agreed with those of Si wafer peaks. We confirmed amorphous structure of SZTO thin films [6,7]. Transfer characteristics of air and wet annealed SZTO TFTs measured at $\mathrm{V}_{\mathrm{DS}}=5.1 \mathrm{~V}$ are shown in Fig.3. Gate voltage $\left(\mathrm{V}_{\mathrm{GS}}\right)$ was swept from $-20 \mathrm{~V}$ to $40 \mathrm{~V}$. Transfer curve shows drain current of log plot (black line) and linear plot (red line). We deduced threshold voltage $\left(\mathrm{V}_{\mathrm{th}}\right)$ by extrapolation method in the linear plot. Table 1 shows the electrical performance of SZTO TFTs with different annealing condition. The field-effect mobility $\left(\mu_{\mathrm{FE}}\right)$ was calculated by using the following relation: [8]

$$
\mu_{F E}=\frac{L g_{m}}{W C_{O X} V_{D S}}
$$

Where, $V_{D S}$ is drain voltage, gm is the transconductance, $C_{o x}$ is the oxide capacitance of the gate insulator, $\mathrm{W}$ and $\mathrm{L}$ are channel width and length, respectively.

In the case of air annealing, the threshold voltage $\left(\mathrm{V}_{\mathrm{th}}\right)$, subthreshold slop (SS), drain current on/off ratio ( $\mathrm{I}_{\mathrm{on} / \mathrm{off}}$ ), and $\mu_{\mathrm{FE}}$ were measured to be about $5 \mathrm{~V}, 1.1 \mathrm{~V} /$ decade, $7 \times 10^{7}$, and 20.4 $\mathrm{cm}^{2} / \mathrm{V}$ s, respectively. For the wet annealing, the $\mathrm{V}_{\mathrm{th}}, \mathrm{SS}, \mathrm{I}_{\mathrm{on} / \mathrm{off}}$, and the field effect mobility were measured to be about $1 \mathrm{~V}, 0.42 \mathrm{~V} /$ decade, 2.6. $\times 10^{8}$ and $24.6 \mathrm{~cm}^{2} / \mathrm{V} \mathrm{s}$, respectively. Based on these results, it is interesting to note that wet annealing treatment can improve the electrical characteristics of the device. This is understood from the generation of free electrons by adopting wet annealing process. Two possible mechanisms could be proposed to explain the performance improvement.

One of the mechanisms is oxygen atoms of a-SZTO film reacting with neighboring hydrogen to generate $\mathrm{H}_{2} \mathrm{O}$. This mechanism can be described as follows: [9]

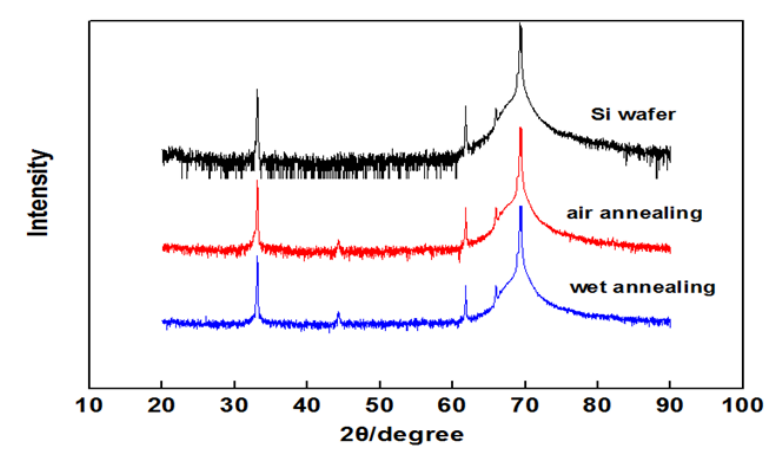

Fig. 2. X-ray diffraction (XRD) spectra of wet and air annealing.
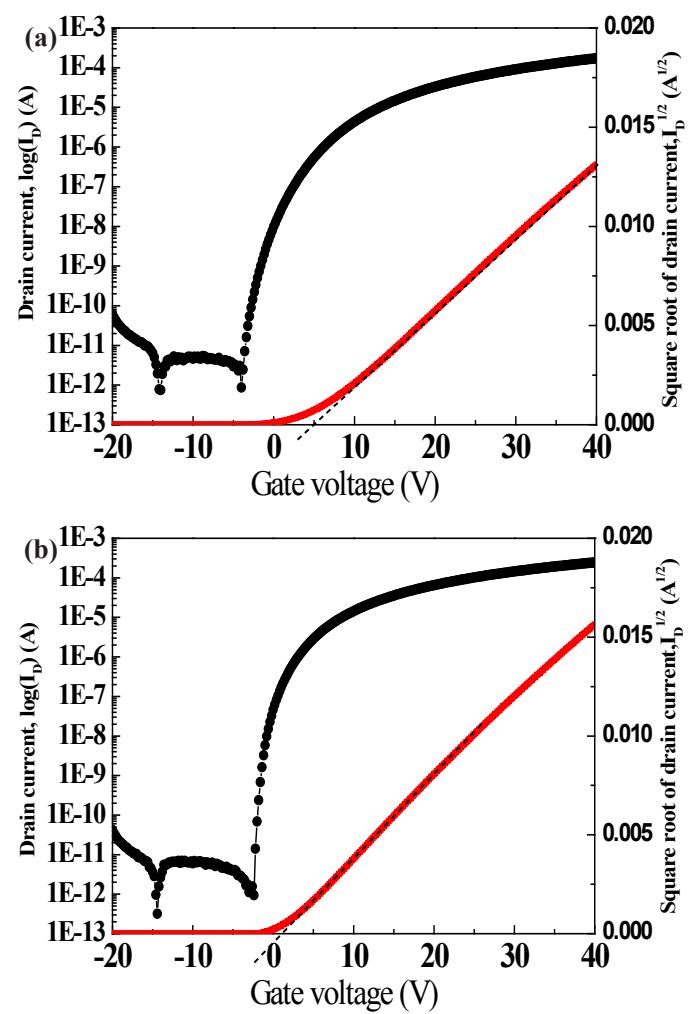

Fig. 3. Transfer characteristic of SZTO TFTs with annealing conditions of (a) air ambient and (b) wet ambient.

Table 1. Electrical performances of SZTO TFTs with different annealing conditions.

\begin{tabular}{ccccc}
\hline $\begin{array}{c}\text { Annealing con- } \\
\text { dition }\end{array}$ & $\begin{array}{c}\text { Threshold } \\
\text { voltage }\left(\mathrm{V}_{\mathrm{th}}\right)\end{array}$ & $\begin{array}{c}\text { Subthreshold slope } \\
(\mathrm{V} / \text { decade })\end{array}$ & $\mathrm{I}_{\text {on/off }}$ & $\begin{array}{c}\text { Mobility } \\
\left(\mathrm{cm}^{2} / \mathrm{Vs}\right)\end{array}$ \\
\hline \hline Air annealing & 5 & 1.1 & $7 \times 10^{7}$ & 20.4 \\
\hline Wet annealing & 1 & 0.42 & $2.6 . \times 10^{8}$ & 24.6 \\
\hline
\end{tabular}

$$
O^{\mathrm{x}}{ }_{\mathrm{o}}+\mathrm{H}_{2}(\mathrm{~g}) \rightarrow \mathrm{H}_{2} \mathrm{O}(\mathrm{g})+\mathrm{V}_{\mathrm{o}}{ }^{-}+2 \mathrm{e}^{-}
$$

where, $\mathrm{V}_{\mathrm{o}}{ }^{\prime \prime}$ is an ionized oxygen vacancy, and e- denotes free electron. The second possibility is the carrier injection by the adsorption of $\mathrm{H}_{2} \mathrm{O}$ on the a-SZTO surface. $\mathrm{H}_{2} \mathrm{O}$ adsorption donates a partial negate charge to the channel surface with either molecules or hydroxyl forms [10]. In this case, the role of $\mathrm{H}_{2} \mathrm{O}$ could be defined as a donor. Consequently, carrier concentration 

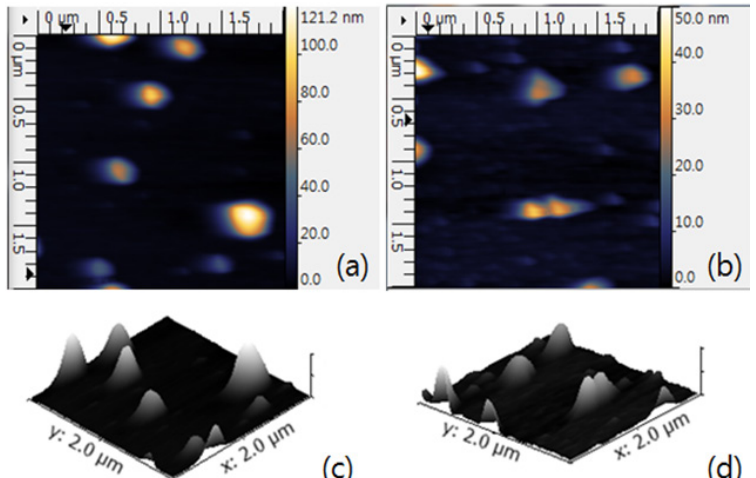

(c)

Fig. 4. AFM images of SZTO thin films (a) air annealing and (b) wet annealing. (c) and (d) are 3D schematics of air and wet annealing AFM data, respectively.
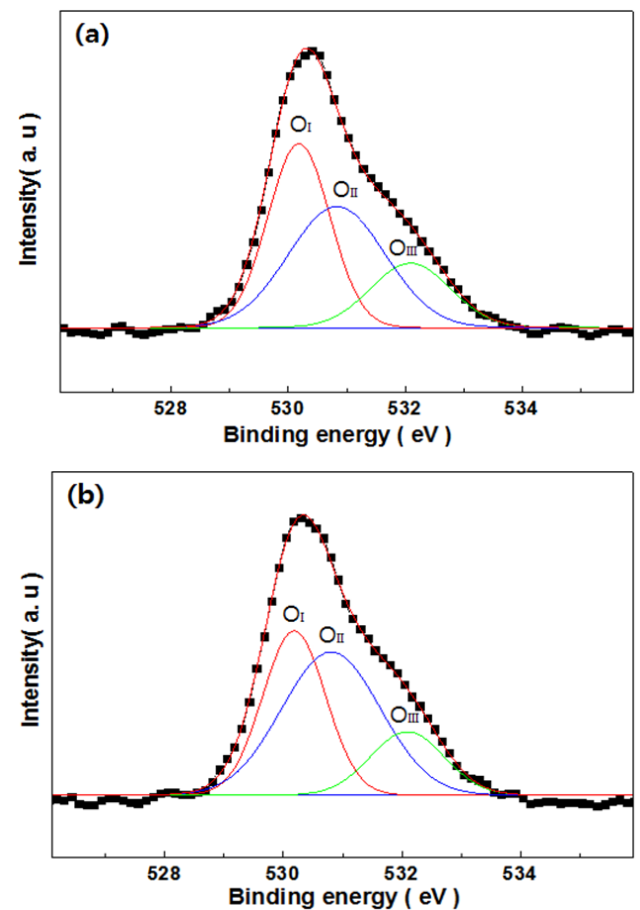

Fig. 5. O1s XPS data of (a) air annealing and (b) wet annealing processed SZTO films.

is increased by wet annealing process. Sub-threshold slope value of wet annealed SZTO TFTs is smaller than that of air annealing treatment. This result can be understood more in detail by analyzing the surface roughness. Figure 4 shows AFM images of air and wet annealed SZTO thin films. The root-mean-squares (RMS) surface roughnesses are measured to be about $16.1 \mathrm{~nm}$ and 5.23 $\mathrm{nm}$ with air and wet annealing, respectively. It shows that surface roughness has been improved more by wet annealing than by air annealing treatment [11]. Figure 5 shows the comparison between the O1s peaks of XPS for the air and wet annealed SZTO thin films. We de-convoluted the O1s peaks into three Lorentzian-Gaussian peaks. The peaks centered at the binding energies of $530 \mathrm{eV}\left(\mathrm{O}_{\mathrm{I}}\right)$, and $531 \mathrm{eV}\left(\mathrm{O}_{\text {II }}\right)$, and $532 \mathrm{eV}\left(\mathrm{O}_{\text {III }}\right)$ were attributed to oxygen ion bonded with neighboring metal atoms, and oxygen vacancy, and presence of loosely bound oxygen on the surfaces
Table 2. XPS O1s result for the air and wet annealed SZTO films.

\begin{tabular}{cccc}
\hline $\begin{array}{c}\text { Annealing } \\
\text { condition }\end{array}$ & $\begin{array}{c}\mathrm{O}_{\text {I }} \text { peak } \\
(530 \mathrm{eV})\end{array}$ & $\begin{array}{c}\mathrm{O}_{\text {II }} \text { peak } \\
(531 \mathrm{eV})\end{array}$ & $\begin{array}{c}\mathrm{O}_{\text {III }} \text { peak } \\
(532 \mathrm{eV})\end{array}$ \\
\hline \hline Air annealing & $40.4 \%$ & $41.4 \%$ & $18.2 \%$ \\
\hline Wet annealing & $35.5 \%$ & $48.5 \%$ & $16 \%$ \\
\hline
\end{tabular}

such as $\mathrm{H}_{2} \mathrm{O}$ and $\mathrm{OH}$ groups, respectively. The $\mathrm{O}_{\text {II }}$ peak value for the air and wet annealed devices were $41.4 \%$ and $48.5 \%$, respectively, as summarized in Table 2 . The area of the oxygen vacancy related peak increased with wet annealing, compare with air annealing. This result is well agreed with the mechanisms described above.

\section{CONCLUSIONS}

In summary, we have fabricated the amorphous SZTO TFTs by $\mathrm{RF}$ magnetron sputtering process, and annealed in the air and the wet ambient. The $\mathrm{V}_{\mathrm{th}}$, SS, and $\mu_{\mathrm{FE}}$ were improved by about $4 \mathrm{~V}$ negative shift, $0.68 \mathrm{~V} /$ decade, and $4.2 \mathrm{~cm}^{2} / \mathrm{V} \mathrm{s}$, respectively, after wet annealing treatment compared with air annealing treatment. In addition, XRD and XPS data showed the amorphous structure of SZTO thin films and the increase of oxygen vacancy. Through this result, it is expected that wet annealing process can improve on the device performance by increasing the free electron concentration.

\section{REFERENCES}

[1] H. Nomura, H. Ohta, A. Takagi, T. Kamiya, M. Hirano, and H. Hosono, Nature, 432, 488 (2004). [DOI: http://http://dx.doi. org/10.1038/nature03090].

[2] E. M. C. Fortunato, L. M. N. Pereira, P. M. C. Barquinha, A. M. B. do Rego, G. Goncalves, A. Vila', J. R. Morante, and R. F. P. Martins, Appl. Phys. Lett., 92, 222103 (2008). [DOI: http://http:// dx.doi.org/10.1063/1.2937473].

[3] J. Y. Choi, S. S. Kim, and S. Y. Lee, J. Nanosci. Nanotechnol., 13, 7089 (2013). [DOI: http://http://dx.doi.org/10.1166/ jnn.2013.7632].

[4] C. Guill'en and J. Herrero, J. Appl. Phys., 101, 073514 (2007). [DOI: http://http://dx.doi.org/10.1063/1.2715539].

[5] S. Park, S. Bang, S. Lee, J. Park, Y. Ko, and H. Jeon, J. Nanosci. Nanotechnol., 11, 6029 (2011). [DOI: http://http://dx.doi. org/10.1166/jnn.2011.4360].

[6] C. Wu, X. Li, J. Lu, Z. Ye, J. Zhang, T. Zhou, R. Sun, L. Chen, B. Lu, and X. Pan, Appl. Phys. Lett., 103, 082109 (2013). [DOI: http:// http://dx.doi.org/10.1063/1.4818728].

[7] E. G. Chong, I. J. Kang, C. H. Park, and S. Y. Lee, Thin Solid Films, 534, 609 (2013). [DOI: http://http://dx.doi.org/10.1016/ j.tsf.2013.02.033].

[8] P. B. Shea and J. Kanicki, J. Appl. Phys., 98, 014503 (2005). [DOI: http://http://dx.doi.org/10.1063/1.1949713].

[9] K. Nomura, T. Kamiya, H. Ohta, M. Hirano, and H. Hosono, Appl. Phys. Lett., 93, 192107 (2008). [DOI: http://http://dx.doi. org/10.1063/1.3020714].

[10] J. S. Park, J. K. Jeong, H. J. Chung, Y. G. Mo, and H. D. Kim, Appl. Phys. Lett., 92, 072104 (2008). [DOI: http://http://dx.doi. org/10.1063/1.2838380].

[11] S. I. Oh, G. D. Choi, H. S. Hwang, W. Lu, and J. H. Jang, IEEE Trans. Electron Dev., 60, 8 (2013). [DOI: http://http://dx.doi. org/10.1109/TED.2013.2265326]. 